\title{
Proton Pump Inhibitors in the Management of Tachypnoea following Panproctocolectomy: A Case of High Output lleostomy
}

\author{
Neville Azzopardia Pierre Ellul ${ }^{b}$ \\ a22, 'Old Charm', Mellieha, and 'Department of Gastroenterology, Mater Dei \\ Hospital, Msida, Malta
}

\section{Key Words}

Loop ileostomy · Ulcerative colitis · Proton pump inhibitors · Gastrin

\begin{abstract}
High output ileostomies are important complications of stoma formation following bowel surgery. Adequate management of such stomas might prevent severe morbidity and mortality when this potentially fatal complication develops. In this case report, we describe a female patient with a recent ileostomy formation following panproctocolectomy for ulcerative colitis who presented with progressively increasing shortness of breath. The patient was found to have a hypochloraemic metabolic acidosis on arterial blood gases. She rapidly improved with adequate sodium and fluid replacement and with the use of a course of proton pump inhibitors. This case highlights the importance of recognising high output ileostomies early and important management issues in their regard.
\end{abstract}

\section{Introduction}

Ileostomy formation is occasionally required in patients with complicated inflammatory bowel disease requiring colonic resection. This procedure can lead to a number of recognised complications including stomal obstruction, stomal prolapse, skin erythema and ileal inflammation. A less commonly described complication is high output ileostomy which occurs when there is a disproportionate fluid and electrolyte loss through the stoma. In the first few days after ileostomy formation, there is frequently an increased stool effluent through the stoma, but this rapidly decreases because of 'ileostomy adaptation' [1]. The normal output through an ileostomy following a total 
colectomy is between 400 and $600 \mathrm{~g}$ of stools daily. In a high output ileostomy, stool output is more than 1,000 g daily, which can result in severe dehydration and electrolyte imbalance [2]. While impaired 'ileostomy adaptation' has been used to describe the pathogenesis of high output ileostomies, there is now an increasing body of evidence suggesting that enteral infection with Clostridium difficile might contribute to the cause $[3,4]$. While it is difficult to estimate the incidence of this complication, it is certainly an important issue which has a significant effect on patients' quality of life and significant morbidity and mortality. Therefore adequate management of high output ileostomies is important. In this article we present a patient with a high output ileostomy and describe the physiological changes that are believed to occur and the recommended management issues of this important complication.

\section{Case Report}

A 42-year-old female lawyer with a 4-year history of ulcerative proctitis presented to our hospital with a 2-week history of worsening shortness of breath at rest, which was worse on exertion. Her colitis was severe and progressive and had extended into a pancolitis. She had failed medical therapy (which consisted of mesalazine $3.2 \mathrm{~g}$ daily since diagnosis, mesalazine enemas, azathioprine at a dose of $2.5 \mathrm{mg} / \mathrm{kg}$ for the previous 4 years and infliximab at a dose of $5 \mathrm{mg} / \mathrm{kg}$ every 6 weeks for the previous 3 years), and 2 months before her current presentation she had undergone a panproctocolectomy with ileal pouch formation and ileoanal anastomosis. A defunctioning loop ileostomy was temporarily performed. Over the years she had also required regular steroids in view of clinically active disease (raised partial Mayo score for ulcerative colitis), blood tests as manifested by anaemia and raised inflammatory markers and endoscopically active disease. Multiple stool samples for culture, ova, cysts, parasites, $C$. difficile toxins and colonoscopic biopsies had ruled out co-existent superinfection. The patient had persistently refused to undergo colectomy until recently.

The patient had no other symptoms besides shortness of breath. On initial assessment she was tachycardic with a heart rate of 130 beats per minute and tachypnoeic with a respiratory rate of 30 breaths per minute and an $\mathrm{SpO}_{2}$ of $93 \%$. The rest of the examination was within normal limits. An electrocardiogram revealed a sinus tachycardia with a $\mathrm{P}$ pulmonale. Chest X-ray was normal. In view of her symptoms, recent surgery and the above findings an echocardiogram was performed, which revealed a hypocontractile right ventricle. A ventilation-perfusion scan excluded any underlying pulmonary emboli. A CT pulmonary angiogram showed no lung pathology and no evidence of pulmonary embolism. Meanwhile her initial blood investigations revealed a hypochloraemic metabolic acidosis on a background of dehydration as indicated in table 1. On more detailed questioning, she had lost $6 \mathrm{~kg}$ since her surgery and had an effluent through the stoma of more than 2 litres per day. A diagnosis of high output stoma was therefore made. Other possible causes of high output stomas such as intraabdominal sepsis, bowel obstruction and infective enteritis were ruled out through the appropriate tests.

She was managed with 1 litre $0.9 \%$ saline 12-hourly and oral fluids with Diarolyte sachets $(0.47 \mathrm{~g}$ sodium chloride per sachet) and an isotonic energy drink ( $0.11 \mathrm{~g}$ sodium chloride per $240 \mathrm{ml}$ of fluid). The patient was not keen on having codeine or Lomotil to slow down the output through the stoma. Thus, she was prescribed omeprazole $40 \mathrm{mg}$ twice daily orally which resulted in a decrease in the effluent through the stoma. On starting this treatment her condition improved rapidly and she was discharged from hospital 6 days later, by which time her blood tests had all normalized. After 3 months the dose of omeprazole was gradually reduced and then stopped and the patient underwent closure of her stoma. Currently she is asymptomatic, has gained weight and is not taking any medications. 


\section{Discussion}

'Ileostomy adaptation' refers to the physiological process that occurs in the small intestine whereby faecal output through a stoma decreases in volume and becomes less fluid. This tends to occur within one to two weeks after ileostomy formation, but may take up to two years [1]. Adaptation is quicker and more pronounced in the ileum rather than in the jejunum. Pathophysiologically, 'ileostomy adaptation' requires cell hyperplasia and increased mucosal surface area with an increase in bowel circumference, an increase in length and bowel wall thickness, and an increase in villus height and crypt depth. Proctocolectomy and the establishment of an ileostomy leads to increased fluid and electrolyte losses even when adaptation is complete, and such patients are susceptible to salt and electrolyte depletion $[2,5]$. A possible complication of this disproportionate increased output of water and electrolytes is a high output ileostomy. This can present itself with dehydration, prerenal impairment, hyponatreamia and hypokalaemia [6]. Our patient presented with prerenal impairment and hyponatreamia associated with a hypochloraemic metabolic acidosis. Serum gastrin is raised in patients who have undergone bowel resection $[7,8]$. Hypergastrinaemia has been shown to cause diarrhoea, possibly due to hyperacidity in the stomach. In fact, patients with gastrinomas tend to present with diarrhoea as their initial complaint in up to $90 \%$ of cases [9].

In the management of high output ileostomies with marked electrolyte and water depletion, replacing fluids by administering 2-4 litres/day of intravenous normal saline is of paramount importance. Keeping the patient starved initially is also important since the net output is driven by the oral intake. Treatment for high output from a stoma begins with the patient restricting the total amount of both oral hypotonic and hypertonic fluids to less than $500 \mathrm{ml}$ per day. The addition of a glucose-saline replacement solution ( $90 \mathrm{mmol} / \mathrm{l}$ sodium or more) is required to make up the total fluid intake.

Loperamide and codeine phosphate reduce intestinal motility and thus decrease water and sodium output from an ileostomy by approximately $20-30 \%$. Loperamide is preferred over codeine phosphate as it is not sedative or addictive and does not cause fat malabsorption. If tablets or capsules are seen unchanged in stool or stomal output, they can be crushed, opened, mixed with water, or put on food.

Drugs that reduce gastric acid secretion (for example, the $\mathrm{H}_{2}$ antagonists or proton pump inhibitors or the somatostatin analogue octreotide) are also commonly used. Ranitidine (300 mg orally twice daily) and omeprazole (40 mg orally daily or intravenously twice daily) reduce stomal output, particularly in those with a net secretory output and generally in those with an output exceeding 2 litres every day. Omeprazole is readily absorbed in the duodenum and upper small bowel but if less than $50 \mathrm{~cm}$ of jejunum remains, it may need to be given intravenously. These drugs, which inhibit gastric acid secretion, are as effective as octreotide (50 $\mathrm{mg}$ subcutaneously twice daily) in reducing the volume of stomal output, but they do not change the absorption of electrolytes and do not reduce stomal output enough to reduce the severity of intestinal failure. Thus, electrolyte replacement will still be necessary.

In adults, octreotide reduces ileostomy diarrhoea and large volume jejunostomy output. The greatest reductions in intestinal output are in those with a net secretory output, and the volume of parenteral supplements needed may be reduced. The reduction in sodium output parallels that of intestinal output while magnesium balance is 
unchanged. Total energy and nitrogen absorption are not significantly changed while fat absorption may be unchanged or reduced. The effect of octreotide is maintained in the long term. Long-acting octreotide or somatostatin preparations have not been assessed in large studies but may prove to be effective in the future. Mineralocorticoids or high-dose hydrocortisone may reduce stomal output in patients with a retained ileum.

Some authors recommend that the management algorithm of a high output ileostomy should include exclusion of small bowel C. difficile, particularly in inflammatory bowel disease patients with a history of previous infection [10]. If Clostridium toxins are found, treatment with oral metronidazole or vancomycin may result in quick resolution of symptoms.

We present a case of high output stoma following bowel resection which was managed by adequate rehydration and proton pump inhibitors. This case highlights the importance of closely following and advising this group of patients with such stomas in order to prevent and identify as early as possible such complications.

Table 1. Initial blood investigations

\begin{tabular}{lll}
\hline Test & Result & Normal \\
\hline Haemoglobin & 10.1 & $11.5-16 \mathrm{~g} / \mathrm{dl}$ \\
Platelets & 463 & $150-400 \times 10^{9} / 1$ \\
WCC & 10.1 & $4-11 \times 10^{9} / 1$ \\
Urea & 24.3 & $2.5-6.7 \mathrm{mmol} / \mathrm{l}$ \\
Creatinine & 113 & $70-150 \mu \mathrm{mol} / \mathrm{l}$ \\
Sodium & 120 & $135-145 \mathrm{mmol} / \mathrm{l}$ \\
Potassium & 4.7 & $3.5-5 \mathrm{mmol} / \mathrm{l}$ \\
$\mathrm{Chloride}$ & 87 & $95-105 \mathrm{mmol} / \mathrm{l}$ \\
$\mathrm{pH}^{\mathrm{pCO}}{ }_{2}$ & 7.29 & $7.35-7.45$ \\
$\mathrm{pO}_{2}$ & 24 & $35-45 \mathrm{~mm} \mathrm{Hg}$ \\
$\mathrm{BE}$ & 77.1 & $75-100 \mathrm{~mm} \mathrm{Hg}$ \\
$\mathrm{HCO}_{3}{ }^{-}$ & -13.9 & $2 \mathrm{mmol} / \mathrm{l}$ \\
$\mathrm{SpO}_{2}$ & 14 & $24-30 \mathrm{mmol} / \mathrm{l}$ \\
$\mathrm{D}^{-d i m e r}$ & 94.2 & $94-100 \%$ \\
\hline
\end{tabular}

Initial blood investigations reveal a hypochloraemic metabolic acidosis and hyponatraemia on a background of dehydration. 


\begin{tabular}{c|l|l|l}
$\begin{aligned} \text { Case Reports in } \\
\text { Gastroenterology }\end{aligned}$ & $\begin{array}{l}\text { Case Rep Gastroenterol 2011;5:212-216 } \\
\text { DOl: 10.1159/000326928 }\end{array}$ & $\begin{array}{l}\text { Published online: } \\
\text { April 13, 2011 }\end{array}$ & $\begin{array}{l}\text { O 2011 S. Karger AG, Basel } \\
\text { ISSN 1662-0631 } \\
\text { www.karger.com/crg }\end{array}$ \\
\hline
\end{tabular}

\section{References}

1 Hill GL, Mair WSJ, Goligher JC: Impairment of 'ileostomy adaptation' in patients after ileal resection. Gut 1974;15:982-987.

-2 Cooper JC, Laughland A, Gunning EJ, Burkinshaw L, Williams NS: Body composition in ileostomy patients with and without ileal resection. Gut 1986;27:680-685.

-3 Lundeen SJ, Otterson MF, Binion DG, Carman ET, Peppard WJ: Clostridium difficile enteritis: an early postoperative complication in inflammatory bowel disease patients after colectomy. J Gastrointest Surg 2007;11:138-142.

4 El Muhtaseb MS, Apollos JK, Dreyer JS: Clostridium difficile enteritis: a cause for high ileostomy output. ANZ J Surg 2008;78:416.

-5 Kanaghinis T, Lubran M, Coghill NF: The composition of ileostomy fluid. Gut 1963;4:322-338.

6 Nightingale J, Woodward JM: Guidelines for management of patients with a short bowel. Gut 2006;55: iv1-iv12.

7 Williams NS, Evans P, King RF: Gastric acid secretion and gastrin production in the short bowel syndrome. Gut 1985;26:914-919.

-8 Tsao SK, Baker M, Nightingale J: High-output stoma after small-bowel resections for Crohn's disease. Nat Clin Pract Gastroenterol Hepatol 2005;2:604-608.

\9 Nightingale JM, Kamm MA, van der Sijp JR, Ghatei MA, Bloom SR, Lennard-Jones JE: Gastrointestinal hormones in short bowel syndrome. Gut 1996;39:267-272.

10 Williams RN, Hemingway D, Miller AS: Enteral Clostridium difficile, an emerging cause for high-output ileostomy. J Clin Pathol 2009;62:951-953. 